\title{
Eco-Energy Analysis in Urban Regeneration Plans: Basic Application in the Eastern Area of Rome
}

\author{
Paolo De Pascali ${ }^{1 a}$, Valentina Alberti ${ }^{1 \mathrm{~b}}$, Daniela De loris ${ }^{1 \mathrm{c}}$, Michele Reginaldi ${ }^{1 \mathrm{~d}}$ \\ ${ }^{1}$ Department PDTA - Planning Design Technology of Architecture, Sapienza University of Rome \\ apaolo.depascali@uniroma1.it, 'valentina.alberti@uniroma1.it, 'daniela@deioris.com, \\ dmichele.reginaldi@gmail.com
}

Keywords: Urban Regeneration, Ecological and Environmental Planning, Urban Comfort.

\begin{abstract}
The article places the urban regeneration theme in the evolutionary context of the general concept of sustainability. The consideration of the environment in terms of exhaustible resources (sources \& sinks), the conception of the urban environment according to EU policies, the vision of sustainability as "efficiency in the transition", are the cornerstones. Then describes the research in progress on the development of an operational methodology to define explicit and replicable bases of the urban environment concept to be considered in plans for urban renewal._Fields of observation and measurement are "comfort" and "anthropogenic load (pollution)". In this regard presents the main results of the ongoing experimental application concerning the eco-energy analysis of the Eastern area of Rome. Finally, gives some general lines for the possible development of research on the topic.
\end{abstract}

\section{Environment in urban planning}

Attention to the environment in urban planning expands the application field and gradually comes to show new connotations linked to the evolution of the debate on the general themes of the sustainability.

Widening the traditional interpretations related to hydro-geological risk and green systems, recently the environmental value in the plan is ever more directed to considering the impacts of the settlements in terms of resources consumption.

The prevailing approach along this route considers as logical foundations the "source \& sink" categories.

Source refers to the elements included in the finite reservoirs, the mindless withdrawal from which significantly reduces the natural endowment and / or irremediably corrupts it; also includes renewable resources for which the utilization rate is greater than that of regeneration, for which these resources are considered like exhaustible.

Sink regards waste generated by the use of the elements of the first category of resources that are conveyed in natural landfill and therefore more or less irreversibly impair these domains and the substances that compose them.

The orthodox conception of sustainability requires maintaining constant levels of the sources and sinks (zero withdrawals from the reservoirs, zero contributions in the dumps), but it is unrealistic to pursue. Especially in urban areas the recent theoretical development for the rehabilitation process introduces the time variable for the pursuit of sustainability, according to the "principle of efficiency in transition": it consists of a double line of action, on the one hand considers the quest for efficiency in the use of natural resources and on the other the progressive construction of the transition towards a settlement pattern zero impact. In general, therefore, the main reference is to the consumption of exhaustible resources resulting from human settlement and the effects that this causes especially in terms of conditions of no return.

This approach appears to be behind the concept of "urban environment" of the EU (assumed as the foundation of the methodology described below) as the result of the impact of settlements in terms of damage (withdrawal and pollution) of the finite natural resources (energy, air, water, natural soil, raw materials, emissions, solid waste, etc..) and the related effects on the ecosystems and the quality of 
human life. This directs the attention towards decoding the phenomenon, universally acquired and undisputed, concerning the considerable impact that the spatial and functional configuration of the settlements on the urban exercises. Nevertheless, it is clear that the impacts produced by the same settlement organization contribute significantly to global environmental conditions.

The event that the overall shape, characteristics and interrelation of the elements that make up the physical structure of the city, contribute significantly to determine the urban environmental quality is widely recognized at least since the Rio Conference in 1992, where was promulgated the Local Agenda 21 and was established the indissoluble link between the local and the global dimension.

Less obvious and mainly less practiced appears the operational development of this assumption with explicit and measurable parameters. That is, the positions of proactive intervention to address the virtuous relationship between the physical city and the urban environment still seems weak and ambiguous, and especially poorly valorized in generality of urban plans.

More generally, it appears that the same discipline of urban planning as it is practiced operationally, but also how it is processed in the methodological paths, encounters major difficulties in dealing proactively with the urban environment in terms of "certain knowledge" of the phenomena that characterize it and the consequent addresses of the plan.

However a new climate of interest in the field of eco energy planning seems to invest the Local Authorities. Determinants result the pressures of the radical policies recently undertaken by the EU in environmental issues that address directly end-users and stakeholders (The 2020 climate and energy package, The Roadmap to a Resource Efficient Europe, Covenant of Mayors, Sustainable competitiveness of the construction sector and its enterprises, etc.).

In essence it is clear that the physiological evolution of what was called "democratic planning" cannot fail to pursue the quality of the urban environment as it is produced by the organization of settlements, in synergy with the statutory originate objectives, such as anti- land rent, adjustment to community facilities and infrastructures, response to housing needs, participation in decisions, equalization effects, etc. This change, expanding structurally the field of the discipline, involves gradually adapting the "genetic code" of urbanism, professional skills and toolbox. In this context, the design process will tend to change the traditional operational approach, focusing on enhancing, in dialectical terms, the pursuit of environmental quality in defining the settlement physical organization.

\section{The experimental methodology in progress}

Despite the acknowledged importance of the aforementioned theoretical framework, one cannot but emphasize the permanence of an operational weakness, which is also determined by the lack of scientific research dedicated to the sector. This should also be considered in the broader context of progressive distance of the planning matter from scientific research, occurring since long time.

The sector of the urban environment on the other hand, in order to effectively configure its structure and align the planning to the issues and problems of contemporaneity, would require vigorous action chain, from basic research to application development, until the transfer of the results and gained knowledge to technicians, administrators, economic actors.

The commitment on this line could allow to resume and deploy the predictive assumptions of Giovanni Astengo towards urbanism as a science, at least in terms of partial but especially in progressive and evolutionary way. The group of the authors of this paper has set up a few years ago several lines of basic research (developed with resources close to the volunteering) that aim to develop experimentally some urban environmental parameters for urban regeneration on the explicit and replicable basis.

In the first phase of defining the field of investigation were extracted the main factors characterizing urban environment which, nevertheless appear to represent the core issues of contemporaneity, are still poorly declined in scientific terms in urban planning:

- Pollution determined by the load of the settlement; 
- Use of fossil fuels with conventional systems;

- Comfort microclimate related to the characteristics of urban space.

These factors are obviously interrelated in relationships cause - effect and their separate treatment turns out to be instrumental, useful mainly in analytical terms, and suitable for the reconstruction phase of the project. This in particular for what concerns the study of the relationship of these factors with the physical and functional organization of the urban system in order to addressing the plan/process toward combined strategies of adaptation and mitigation, according to the approach used by the European Environment Agency. The ultimate aim is the pursuit of urban sustainability according to the conceptual relativism of the transition. The explicit character of these factors allows the measurement as - quantitative indicators of the observed phenomena and enables the consequent graphical representation with the help of indirect variables given the lack of specific environmental and disaggregated data.

The experimentation developed refers to a process plan; which focuses on the intermediate planning dimension defined not so much and not only according to the rules of L. Quaroni as intermediate point between plan and project, but as a cross between a top-down path, for example, the General Plan (PRG) or the plan of the metropolitan area, and a bottom-up path resulting from participatory procedures and therefore physiologically generated in limited areas.

It is believed that at the meeting of these two pathways (descending and ascending) can be effectively intercepted the above-mentioned environmental factors, as well as the total binder of the content and parts of the master plan. The environmental value arises then additional terms rather than replace the traditional content of the plan. However, it assumes a structural character as it tends to perturb and in any case to permeate the other parameters converging in the process.

The characterizations of the environment as well as previously established are particularly evident in the compact urban periphery as that of the East Area of Rome where it is placed the experimentation and where it is proposed a hypothesis of comparison and integration of these issues with the addresses of the new General Plan (PRG).

The diagram in Fig. 1 shows the methodological route adopted in the first phase of experimental application. This route follows two main directions of investigation relating to: the assessment of urban comfort (large scale), and the determination of the anthropogenic load in terms of pollution.

\section{Ecological and environmental factors in urban planning}

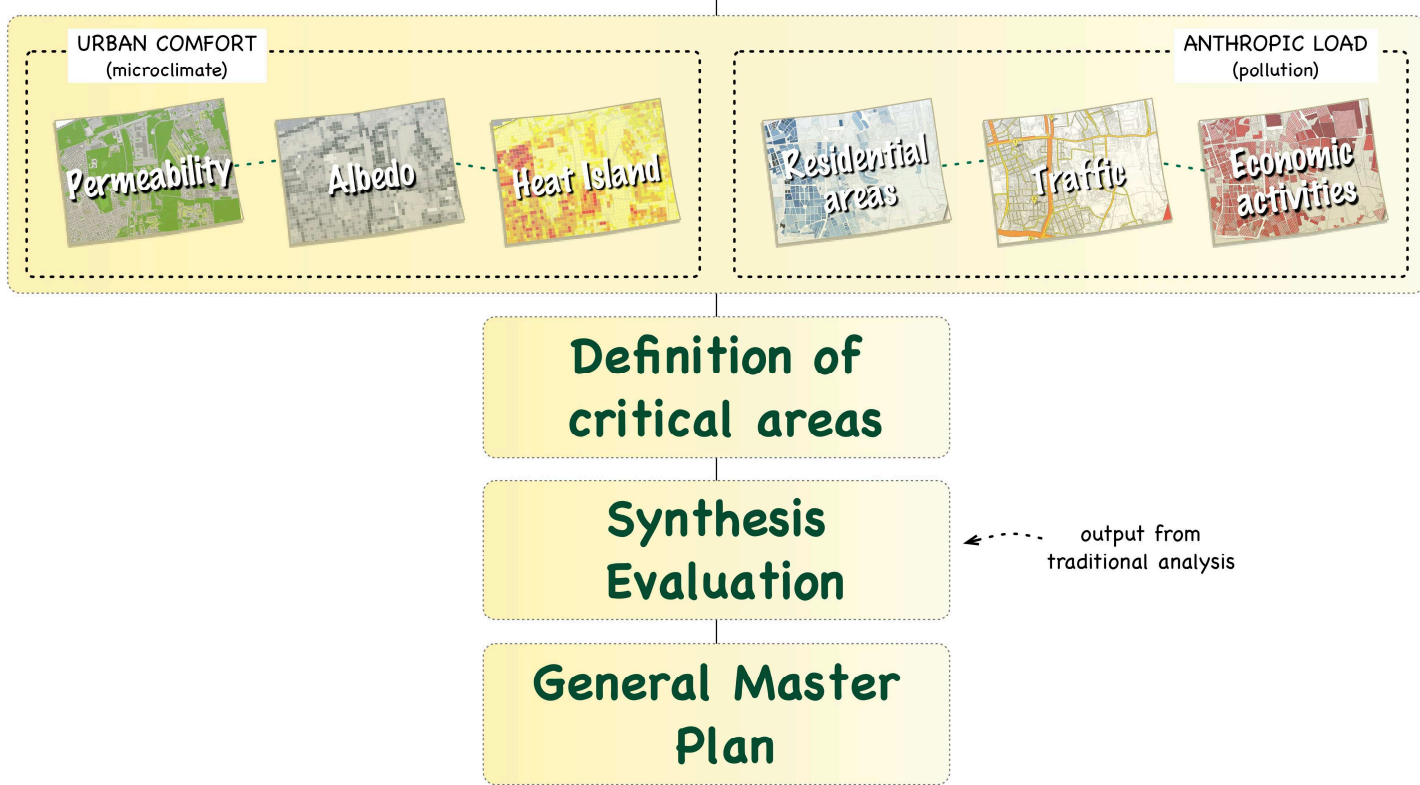

Fig.1 - Methodological route 
The urban comfort is evaluated according to three main parameters related to:

- Permeability of soils, as a potential evapo-transpiration capacity of the soil; substantially corresponds to a index coverage / natural soils;

- Albedo, as reflected fraction of solar radiation due to the color and nature of the surface materials and the parts of the settlement (refer with: Fig. 2);

- Urban heat island, representing the result of the preceding factors plus others (thermal trap, entropic heat, pollution, particulate matter, etc.). useful in locating the main urban conditions of discomfort in our latitudes in terms of microclimate, the evaluation is done by parametric simulations (refer with: Fig. 3).

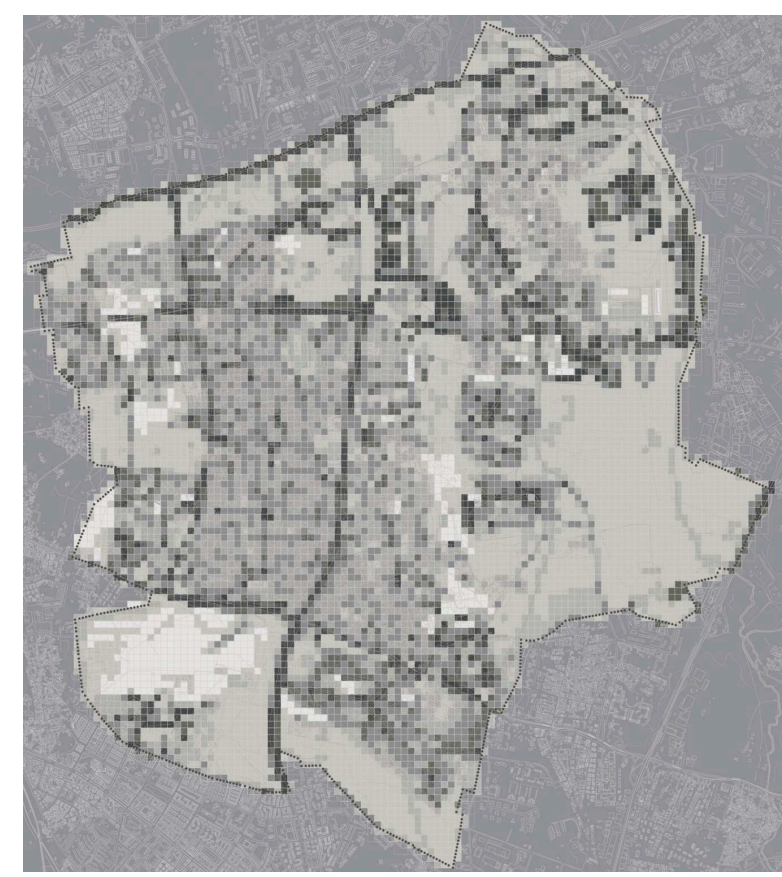

Fig.2 - Albedo

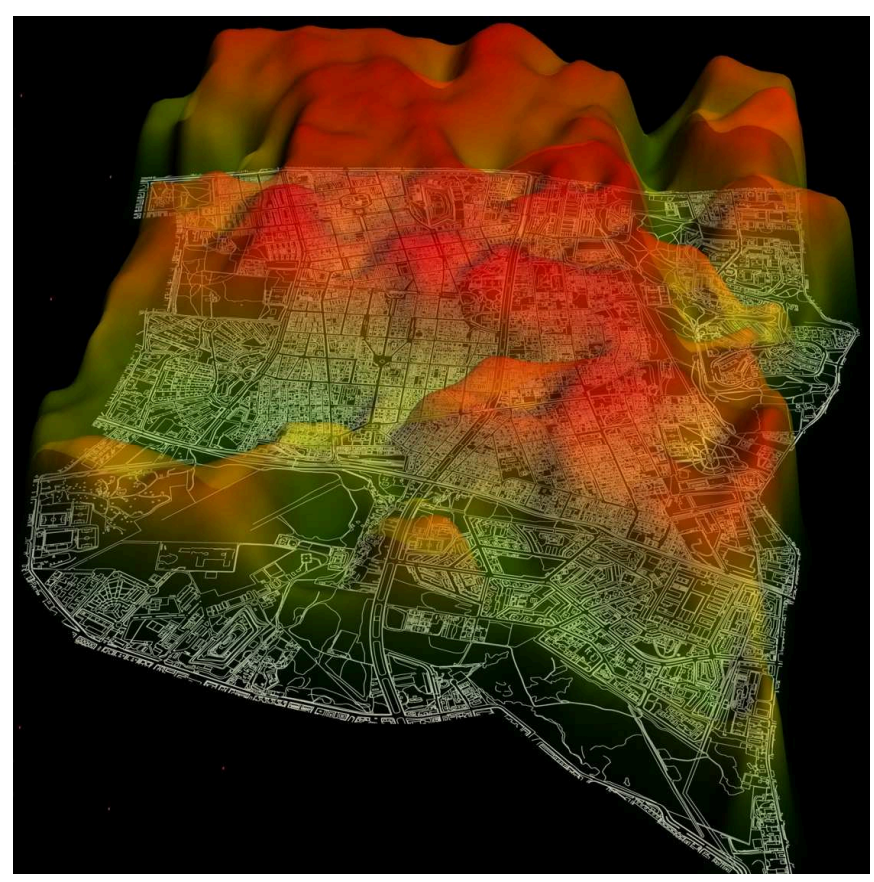

Fig.3 - Urban heat island

The anthropogenic load (pollution) is considered on the basis of the contributions of activities / functions grouped in three areas: load from residence (see example in Fig. 4), load from transport, load from industry.
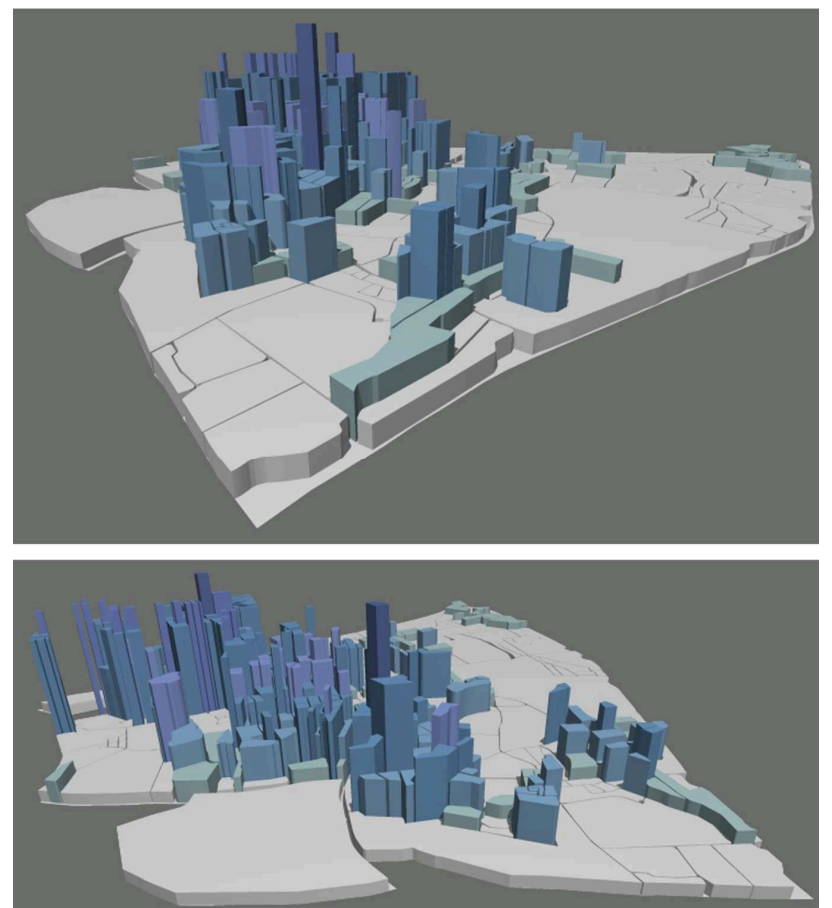

Fig.4 - Residential load

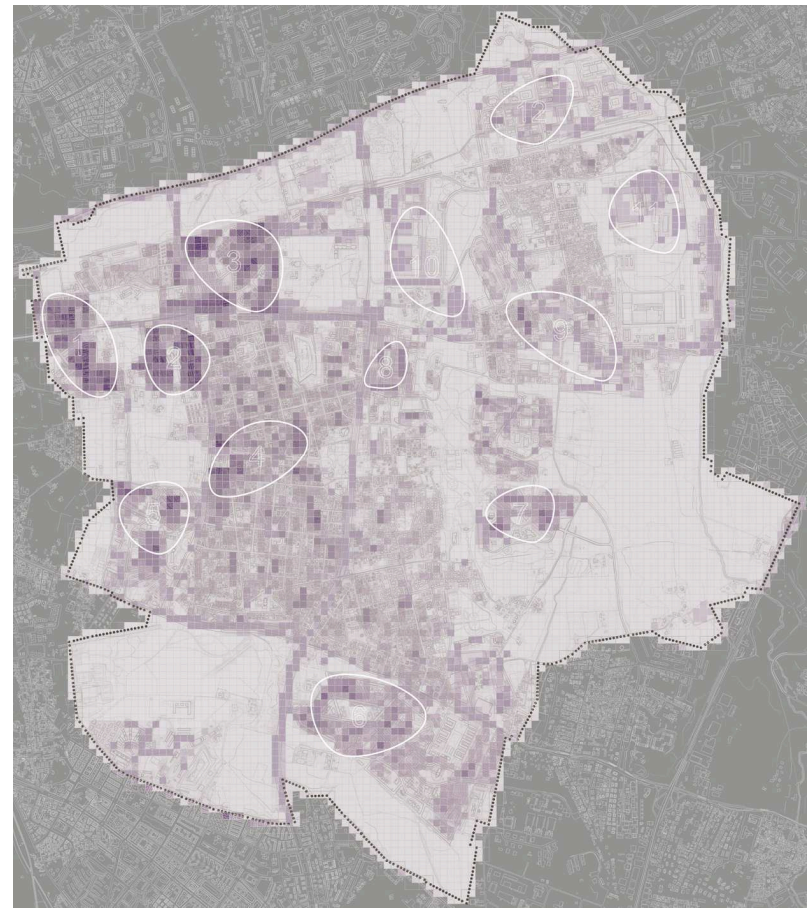

Fig.5 - Critical areas 
A specific line of research concerns the study of innovative graphics solutions for the phenomena spatialization, with the aim of producing most representative images of the traditional ones.

The analysis integration leads to the definition of the areas most critical from the environmental point of view (refer with: Fig. 5); from analysis descends synthesis evaluation that also incorporates the results of other analyzes; the synthesis represents the basis for producing the general master plan.

More in-depth analysis on urban comfort are carried out on a smaller scale (refer with: Fig. 6) using specific simulation software (Townscope III).

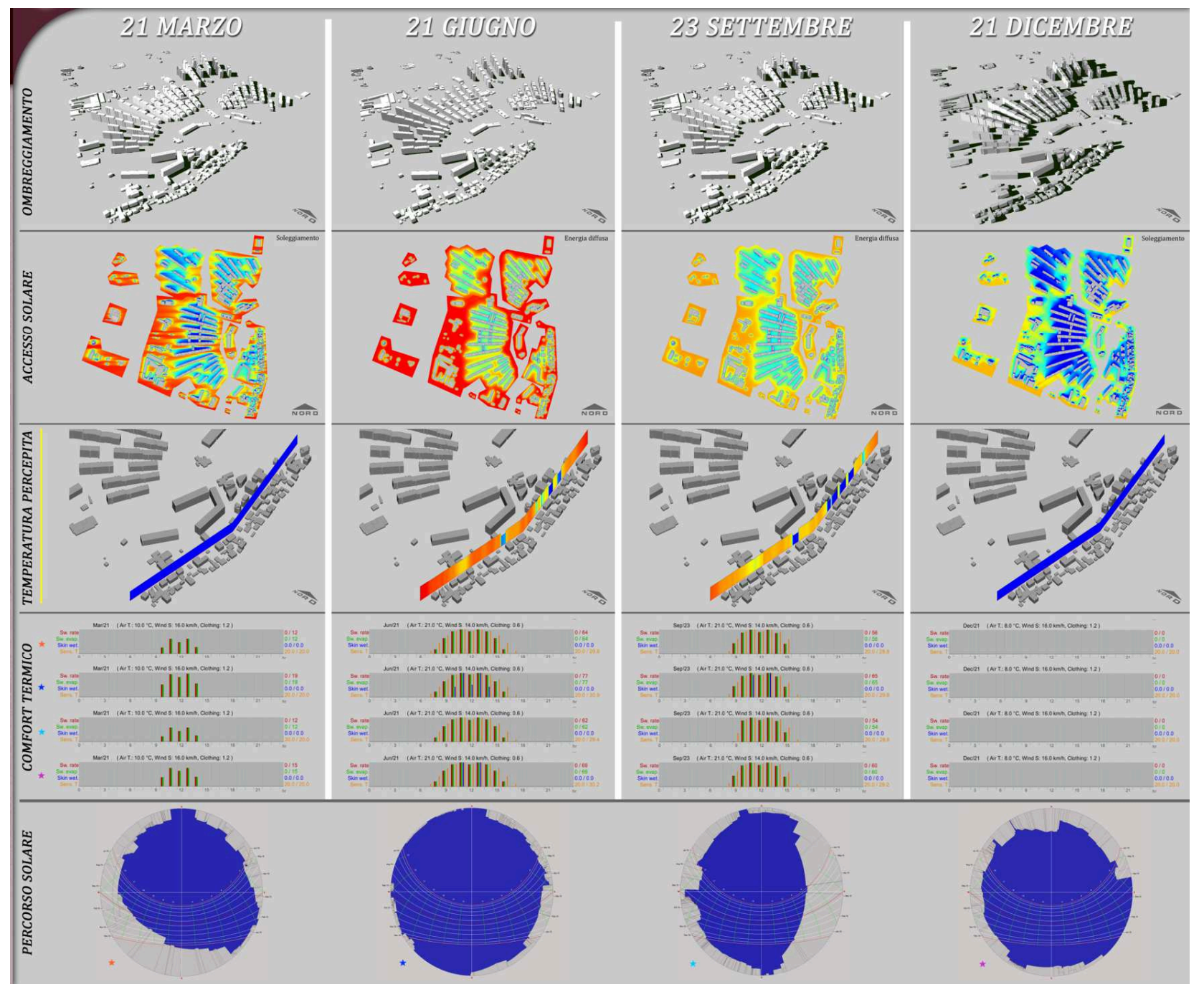

Fig.6 - Detailed urban comfort simulation

\section{A research direction for urban regeneration}

The start of urban renewal programs met and still meets considerable difficulties. The ratio heavily unbalanced among the growing number of disused spaces in the periphery and the few areas rehabilitated, amply demonstrates these difficulties, even a superficial observation. The current situation of deep economic crisis does not seem to create favorable conditions for the change of trend in the near future. Actually the crisis highlights the ongoing decline of the construction sector that seems to irreversibly lose the economic driving force, both at a general level but also widely in local situations.

In this context, the force for urban transformation coming from the real estate market appears to have significantly weakened, other engines, more shaped to the contemporary situation, are required to be employed for urban regeneration. 
In this sense, the eco energy sector seems to have the potential of becoming one of these engines also for its significant economic potential, for congruence with the stringent EU policies, for compliance with collective demand and opportunities for social inclusion that it presents.

The two powerful processes of change in progress, regarding the devolution of powers in the territorial government and the liberalization of the energy market, tend to converge towards the enhancement of energy localism and the role of energy in paths of settlement rehabilitation.

This change of system from central to local dimension opens to the possibility of adopting a more intense relationship than the one currently in use between the planning of settlements and eco energy programming. This change aims at emphasizing the ecological component in settlements transformation, that is structuring planning process from the côté energy - ecology.

The energy component can be the factor that pulls the strings in the plan for its systemic value in the pursuit of settlement quality, social inclusion and economic models of proximity that are combined with the energy of proximity.

It opens a profitable field of research for urban planning so far largely unexplored concerning the definition of the spatial - organizational characteristics of settlement rehabilitation with eco energy value, within the participatory and inclusive social models.

Energy efficiency and ecological value can be considered as the backbone of the urban plan, that is, as structural factors to pursue the improvement of settlement. It may be taken, at the stage of setting of the plan, as a basis to determining intervention unit (basin / district), optimal mix of functions, size of intervention, infrastructure system and displacements, in general terms the overall physical functional organization of the city.

This new approach, promising large potentialities, needs deep and continuous research activities in order to build the plan / process "eco - energy driven".

\section{References}

[1] Daly, Herman: Steady-State Economics, Island Press, Washington, DC (1991)

[2] T. R. Oke: Canyon geometry and nocturnal urban heat Island: comparison of scale model and field observationss. In: Journal of climatology 1 (1981)

[3] Peter Droege: The Renewable City, John Wiley \& Sons Ltd, England (2006)

[4] P. De Pascali: Città ed energia. La valenza energetica dell'organizzazione insediativa, FrancoAngeli, Milano (2008)

[5] P. De Pascali, V. Alberti, D. De Ioris, G. Di Pasqua, M. Reginaldi: Temi di sostenibilità eco energetica, Orienta, Roma (2013)

[6] Commission of the European Communities, Communication from the Commission to the Council and the European Parliament on Thematic Strategy on the Urban Environment. Information on: http://ec.europa.eu/environment/urban/pdf/com_2005_0718_en.pdf

[7] G. Astengo: definition of "Urbanistica", Enciclopedia Universale dell'Arte, vol. XIV, Venezia (1966)

[8] EEA, Urban adaptation to climate change in Europe, EEA Report n. 2/2012; Information on http://www.eea.europa.eu/publications/urban-adaptation-to-climate-change

[9] EU environmental policies (mentioned in the text):

Information on http://ec.europa.eu/clima/policies/package/;

Information on http://ec.europa.eu/environment/resource_efficiency/about/roadmap/index_en. htm; Information on http://www.covenantofmayors.eu/index_en.html;

Information on http://ec.europa.eu/enterprise/sectors/construction/studies/sustainablecompetitiveness_en.htm 